\title{
SUMMARY OF DISCUSSIONS
}

\author{
by
}

Mark F. Meier

(Institute of Arctic and Alpine Research, University of Colorado, Boulder, CO 80309, USA)

In 1965, the first International Symposium on Glacier Mapping was held in Ottawa. This was convened at the beginning of the International Hydrological Decade, at a time of great expansion in glaciological research around the world. The purpose and scope of glacier mapping were well defined, perhaps for the first time, by the late Valter Schytt and others at the Symposium. It must be remembered that this symposium took place at a time when much of the technology we now take for granted did not exist. In some respects the symposium was prophetic: Gordon Robin suggested that the topography of the ice sheet might be measurable with an altimeter mounted in a satellite, and A.H. Waite, Jr. discussed the beginning attempts to sound glaciers using radio waves.

Now in 1985 a Symposium on the same subject has been concluded in Reykjavik. It is apparent that the interest generated in the first Symposium has had a real effect, and some dreams have come true. Jay Zwally reported that repeated satellite altimetry has measured growth of part of the Greenland Ice Sheet, and sophisticated radio echo-sounding programs are adding the third dimension to glacier mapping. And glacier mapping has progressed in many other new and exciting directions. However, problems remain. For instance, only $20 \%$ of the Antarctic continent has been mapped at a scale of 1:250000 or larger and what maps do exist of Antarctica were compiled over long periods of time and cannot be precisely dated. There are still few maps of remote areas in the world and these of ten lack geographic coordinates and captions in a language of common international use. The navigation or positioning systems used in many large-scale mapping programs have not been as highly developed as they should be. Much glacier mapping data now exists in digital form, but many of the digital data bases can not be accessed internationally.

What are the needs for the future? First, we need wider application of digital data bases, including digital terrain models and geographic information systems. These should be set up so that the data can be retrieved by scientists from different countries, a difficult problem for parochial, technical, and political reasons. Attention needs to be given to long-term storage of digital data to insure against degradation with time. Once a good digital data base is established, the appropriate hard copy maps can be produced to whatever specifications are appropriate.

But computers will not solve everyone's needs. We certainly will need, far into the future, classical paper maps, the so-called "hard copy" that displays all of the information the field glaciologist or traveller requires. Public display maps that show the topography in an artistic way that is clear to the inexperienced viewer will always be needed. Of course, all maps should have geographic coordinates and a legend in an international language, such as English, to meet the needs of the international community.

The quality of mapping will have to improve to meet tomorrow's needs. This will include such things as improved definition of ice sheet surfaces, especially along ice divides so that flow patterns can be discerned. We need to integrate accurate positioning systems with the radio echo-sounding or other mapping systems. Repeated mapping of certain glaciers or ice mass areas, using similar mapping specifications, will be needed to detect change in these ice masses; such maps will have to be very precise in the measurement of surface ice elevation. We will certainly need "snapshot" maps of the large ice sheets, a task that can probably be accomplished only through the use of satellite technology. The field has come a long way in the last twenty years but it will probably progress far more in the next twenty.

I wish to thank all of the speakers and the participants and those who so superbly organized the Symposium for a most challenging and productive meeting. Thank you all very much. 